\title{
“¡Niños, seamos buenos, miremos ese horror!”. El nacionalismo cívico como régimen emocional en la educación chilena durante la segunda guerra mundial (c.1941-c.1945)
}

\section{('Children, let's be good, let's look at that horror!' Civic nationalism and emotional rule in Chilean education during World War II}

(c.1941-1945)

\author{
Pablo TORO-BLANCO \\ Universidad Alberto Hurtado (Chile)
}

\begin{abstract}
RESUMEN: El propósito del artículo es presentar un análisis sobre los mensajes de pacifismo, integración continental y defensa de la democracia formulados en comunicaciones oficiales de las autoridades educacionales chilenas a propósito de la Segunda Guerra Mundial, percibida tanto como un conflicto geográfica y materialmente lejano, pero de alto potencial de impacto sobre la vida de chilenas y chilenos. El estudio que acá se presenta se realiza a partir del análisis del contenido de los documentos disponibles, empleando un enfoque que privilegia la búsqueda de textos que permiten caracterizar patrones discursivos relacionados con términos significativos en relación al conflicto (paz, guerra, integración latinoamericana, democracia) y al foco teórico que sustenta la búsqueda: la formación de regímenes emocionales.
\end{abstract}

PALABRAS CLAVE: pacifismo; nacionalismo cívico; régimen emocional; educación chilena; historia transnacional.

ABSTRACT: This article examines the messages of pacifism, continental union and defence of democracy issued in official communications by the Chilean educational authorities during World War II, a conflict perceived as geographically and materially distant, but with potentially serious repercussions for Chile and its people. The study uses a content analysis approach to identify discursive language patterns related to the international conflict of the time (peace, war, Latin American union, democracy) and the formation of emotional regimes.

KEYWORDS: pacifism; civic nationalism; emotional regime; Chilean education system; transnational history. 


\section{Introducción}

La frase que sirve de pórtico a estas páginas fue escrita por la niña Hortensia Vera, en noviembre de 1943. Impactada por las noticias acerca del sufrimiento de las niñas y niños polacos, víctimas inocentes de un conflicto cruento y devastador, Hortensia probablemente intentaba, imaginamos, un doble propósito con su composición escolar "Oración a los Niños Polacos", que llegó a ser destacada en su escuela, recorrió el tránsito de la administración escolar chilena y terminó publicada en letras de molde en un medio oficial. ${ }^{1}$ Por un lado, a través de la distancia inconmensurable, la niña chilena buscaba arrojar al viento palabras de consuelo y solidaridad hacia las sufrientes víctimas infantiles de la ocupación nazi esperando que, de alguna improbable manera, llegaran a su destino. Por otra parte, con mayores posibilidades de cumplir su deseo, Hortensia se dirigía a niñas y niños más cercanos: quería impactar afectivamente a quienes leyeran su poema y provocar en ellos un sentimiento de solidaridad con la infancia polaca. No conocemos toda la trama que llevó a la estudiante Vera a escribir su Oración (¿espontánea manifestación emocional y artística, recogida por su profesor y conducida a su publicación? ¿producto de una tarea escolar que debía ser cumplida sí o sí?), pero sabemos a ciencia cierta, al menos, que es un reflejo concreto de un amplio campo de acciones de política educativa que fueron propuestas desde las autoridades centrales con el propósito de inspirar, a través del conjunto del sistema escolar chileno, expresiones afectivas en torno al lejano fenómeno de la guerra, inscritas en la promoción de ideales tanto nacionalistas como cosmopolitas: formas de inducción emocional para valorar lo propio, celebrar la paz y sensibilizar a niños y jóvenes frente a un orden global en conflicto.

El propósito de estas páginas es presentar un análisis sobre los mensajes de pacifismo, integración continental y defensa de la democracia que se encontraban formulados en comunicaciones oficiales de las autoridades educacionales chilenas a propósito de la Segunda Guerra Mundial, percibida como un conflicto geográficamente lejano, pero de alto potencial de impacto sobre la vida de chilenas y chilenos. Los versos de Hortensia Vera se erigen en testimonio de cómo, en un orden transnacional cada vez más evidente, los sucesos acontecidos a miles de kilómetros de distancia fueron ocasión para intentar movilizar emocionalmente a la infancia y juventud escolarizadas de un país que persistió durante varios años en sostener una posición de neutralidad frente a los bloques en conflicto. Así, a partir del impacto general que la Segunda Guerra Mundial causó en Chile, en este texto se da relieve a algunas dimensiones específicas. De tal modo, se concentra principalmente en el ámbito educacional público, explorando los discursos y medios a través de los cuales determinados conceptos fueron siendo fortalecidos en liceos y escuelas con el propósito de generar un lenguaje común que fuera apropiado para procesar el fenómeno de la guerra y estimular actitudes y valores pacifistas, integracionistas y democráticos, en el marco del singular contexto político de una alianza gobernante hegemonizada por el partido radical (que gobernó Chile entre 1938 y 1952), la que, en términos generales y en buena parte de sus períodos presidenciales, tuvo posturas de centroizquierda y promovió

${ }^{1}$ Hortensia Vera, "Oración a los Niños Polacos", Boletín de Educación (1943): 27. 
un nacionalismo cívico ad-hoc. La formación de este discurso, de orientación policlasista, integracionista, desarrollista y con altas expectativas depositadas en la promoción de la educación pública como factor de cohesión social frente a las fuerzas desafiantes al orden liberal-democrático, puede ser comprendida como un proceso que se articula en Chile desde la crisis del Centenario (1910) en adelante, habiendo sido estudiada consistentemente para sus primeras décadas por el historiador norteamericano-chileno Patrick Barr-Melej. ${ }^{2}$

El estudio que acá se presenta se realiza a partir del análisis del contenido de los documentos disponibles, empleando un enfoque que privilegia la identificación de alusiones que permitan detectar patrones discursivos relacionados con el conflicto (paz, guerra, integración latinoamericana, democracia) y con el foco teórico que sustenta la búsqueda: la formación de regímenes emocionales. Por ello, se considera, de manera referencial, la orientación conceptual general de William Reddy, que los define como "el conjunto de normas emocionales, rituales y prácticas oficiales y emotives que las expresan y las inculcan y que constituyen el sustento de cualquier régimen político estable"3. En la propuesta de Reddy (de la que solamente se recoge en estas páginas sus implicancias respecto a la normatividad, dejando pendiente su complejidad explicativa en base al ensamble entre lo lingüístico y lo performativo) se puede apreciar la función afectiva no solamente (aunque sí preponderantemente) del lenguaje, sino que también de la estética, la corporalidad, la materialidad ${ }^{4}$. Además del uso selectivo de la idea de régimen emocional, en estas páginas se tiene como referencia ejemplos historiográficos en los que las dimensiones emocionales han impactado o pretendido impactar la política o la escuela ${ }^{5}$. Para lograr el propósito indicado, se recurre a dos tipos de fuentes principales: publicaciones oficiales del ámbito educacional (que entregan el discurso normativo y exhiben los énfasis respecto a los conceptos que habrían articulado un régimen emocional frente a la guerra y por la paz) y testimonios provenientes de establecimientos escolares (prensa estudiantil, reportes internos de liceos, bitácoras escolares), cuyo uso cumple el propósito de detectar, en la medida de lo posible, aspectos de la apropiación y materialización de las orientaciones oficiales. Lo anterior es complementado, en los casos donde es viable y/o pertinente, con el uso de prensa periódica y literatura de la época.

\footnotetext{
${ }^{2}$ Al respecto, es recomendable consultar Patrick Barr-Melej, Reforming Chile: Nationalism, and the Rise of the Middle Class (Chapel Hill: University of North Carolina Press, 2001).

${ }^{3}$ William Reddy, The navigation of feeling. A framework for the history of emotions. (Cambridge: Cambridge University Press, 2001), 129. (La traducción del fragmento es nuestra).

${ }^{4}$ Una observación crítica acerca del excesivo peso concedido a la palabra escrita como fulcro de los regímenes emocionales se formula en el texto de Jan Plamper "Historia de las emociones: caminos y retos", Cuadernos de Historia Contemporánea 36 (2014): 25.

${ }^{5}$ Sobre el impacto de los aspectos afectivos en la política, ver Nicole Eustace, "Emotions and political change", en Doing emotions history, ed. Susan Matt y Peter Stearns (Urbana: University of Illinois Press, 2014), 163-183. Acerca del nacionlismo en la escuela chilena, algunos elementos en Pablo Toro-Blanco, "Como se quiere a la madre 0 a la bandera: "Notas sobre nacionalismo, ciudadanía y civilidad en la educación chilena (1910-1945)", en Nacionalismos e identidad nacional en Chile. Siglo XX, ed. Gabriel Cid y Alejandro San Francisco (Santiago: Ediciones Bicentenario, 2010), I, 133-158.
} 
La estructura de este texto consta de un primer apartado en el que se presenta un marco de referencia respecto a las características relevantes del discurso educacional chileno frente al conflicto armado global. En dicho discurso se inscriben variadas iniciativas que concurrieron hacia la formación de un régimen emocional. En seguida, se abordan brevemente algunos ejemplos que dan pie para examinar la existencia de dicho régimen emocional cívico y pacifista frente a la guerra y, por último, se plantean algunas reflexiones sobre los vínculos entre escuela y formación emocional como dispositivo político nacionalizador y democratizante.

\section{El discurso educacional frente a la guerra}

Es un lugar común historiográfico que la Segunda Guerra Mundial significó una especie de breve nueva emancipación para América Latina, ya que supuestamente la dependencia respecto a las economías centrales y su intervención política directa se debilitó debido a la conflagración. Más allá de cuán precisa sea esa idea, es claro que la Segunda Guerra Mundial dio un lugar más amplio a nuevos discursos políticos en América Latina, la mayoría de ellos con un fuerte compromiso con el nacionalismo, el latinoamericano y la protección de la democracia también. Los sistemas educativos no estuvieron ajenos a esa ola retórica, combinando en diversa medida estos elementos. En el caso de Chile, las autoridades educativas trataron de promover los valores nacional-democráticos a través de una infinidad de medios diferentes, con énfasis en la amenaza que el totalitarismo y la guerra significaban para aquellos países que no estaban directamente involucrados en el conflicto.

En el sistema educativo chileno la promoción oficial de un nacionalismo progresista y cívico tuvo la oportunidad de ser reforzada a medida que evolucionaba la amenaza de la Segunda Guerra Mundial. Los rituales patrióticos y cívicos fueron acompañados con frecuentes menciones a la situación europea y sus amenazas contra la democracia. A pesar de que en los últimos años la historiografía ha abordado algunos temas críticos acerca del nacionalismo educativo en Chile, como se puede ver en el trabajo de investigación de historiadores como Stefan Rinke o Patrick Barr-Melej, el impacto directo de la Segunda Guerra Mundial en la educación chilena ha recibido poca atención ${ }^{6}$. Aunque la guerra fue una amenaza distante, dada la ubicación periférica de Chile, jugó un papel como una referencia de peligro para los valores políticos que el gobierno chileno alentaba. En este sentido, uno de los dispositivos más destacados para percibir la política educacional del Gobierno al respecto son los mensajes oficiales como, por ejemplo, los del Ministro de Educación de Chile, Benjamín Claro Velasco. Concebidos originalmente como una serie de folletos que llegarían a todas las escuelas de Chile, finalmente fueron compilados en un libro publicado en 1945. Al evaluar el conjunto de sus Mensajes, Claro Velasco comenzaba su libro recordando lo que había formulado al iniciarlos:

\footnotetext{
${ }^{6}$ Stefan Rinke, Cultura de masas, reforma y nacionalismo en Chile 1910-1931 (Santiago: DIBAM, 2002) y Encuentros con el Yanqui. Norteamericanización y cambio sociocultural en Chile (1898-1990) (Santiago: DIBAM/ LOM, 2014); Barr-Melej, Reforming Chile.
} 
gracias a la cooperación dada por los directores de las escuelas, estas cartas se leerán en todas las escuelas públicas y espero que también en las escuelas privadas. Las sugerencias que contienen serán escuchadas, por lo tanto, por casi todos los 680.000 niños y jóvenes que asisten, al mismo tiempo que ustedes, a escuelas, institutos y escuelas secundarias. ${ }^{7}$

Se requiere una breve explicación sobre la naturaleza de los Mensajes como dispositivo educativo para una mejor comprensión del proceso con el que estamos tratando. En sentido estricto, el libro que los compiló no encajaba en la categoría de material regular educativo. En primer lugar, porque no se trataba de un libro de texto perteneciente a una asignatura específica de la escuela y, por lo tanto, no tenía asociado ningún tipo de actividades didácticas. En segundo lugar, y más importante para nuestro interés, los Mensajes, a pesar de su formato escrito, estaban destinados a ser interpretados como discursos, 0 sea, performances públicas que comprometían un conjunto amplio de sentidos tanto en los emisores como en los receptores. El modo como estaban construidos los discursos resulta interesante, en la medida que siempre involucraba una interpelación directa a las y los estudiantes. Así, por ejemplo, Claro Velasco buscaba establecer de manera directa un vínculo emotivo y moral entre el acontecer mundial y la vida íntima de cada alumno, afirmando que "en verdad, las mismas fuerzas de progreso o estagnación que se debaten en el escenario del mundo, se están enfrentando, en cotidianos y silenciosos combates, dentro de la pequeña órbita de acción de cada uno de vosotros" De tal manera, en marzo de 1943, el ministro les sugería a los niños y niñas que su comportamiento diario, eligiendo entre ser amables o malos entre sí, era una pequeña guerra que formaba parte, mediante su ampliación a escala global, de los conflictos dramáticos por los que estaba atravesando el mundo. ${ }^{8}$

Independientemente de que cualquier tipo de mensaje sea siempre parte de un ciclo interpretativo o de un flujo de comunicación no totalmente regulado, la obligación administrativa de las autoridades escolares de leer las palabras de Claro Velasco probablemente dio menos espacio a los intérpretes locales para remodelar en profundidad sus contenidos. No es aventurado pensar que los Mensajes efectivamente hayan sido leídos y comentados por directores y directoras de escuelas a lo largo y ancho de todo el país, pues existen testimonios recogidos a partir de archivos de establecimientos educacionales que permiten corroborar que, efectivamente, los discursos eran leídos en asambleas generales de profesores y estudiantes y/o durante los denominados "actos cívicos" con los que se inauguraban regularmente la semana de estudios. Así, por ejemplo, lo refleja la bitácora de un Liceo en la sureña localidad de San Fernando: "miércoles 22 de marzo de 1944: el profesor del establecimiento, Don Osvaldo Castillo Peña en un acto escolar ante todos los alumnos reunidos, leyó el mensaje Consigna, el noveno del Sr. Ministro de Educación Pública a los alumnos de las Escuelas, institutos y Liceos de Chile". Por su parte, las estudiantes del

\footnotetext{
${ }^{7}$ Benjamín Claro Velasco, Mensajes a los niños de Chile, marzo de 1943-octubre de 1944 (Santiago: Ediciones de la Universidad de Chile,1945), 9.

${ }^{8}$ Ibidem, 22.

${ }^{9}$ ALNSC (Archivo del Liceo de Hombres Neandro Schilling de San Fernando). Vro06 Crónica del Liceo de Hombres de San Fernando. 1931-1944, 29.
} 
Liceo 1 de Niñas de Santiago escucharon el mismo discurso, leído por su profesora, la señorita Amanda Cañas, el lunes de la semana anterior, como quedó reflejado en el libro de actas del Liceo. ${ }^{10}$

Más allá de cuán literales hayan sido las lecturas públicas de las palabras de Claro Velasco a los estudiantes chilenos, lo cierto es que los Mensajes podrían entenderse como parte del dispositivo de política educativa que perseguía objetivos tácticos y estratégicos: a largo plazo, formaban parte de un vasto plan firmemente dedicado a ampliar una versión local de aquellos propósitos nacionalistas que los sistemas educativos latinoamericanos estaban expandiendo desde, al menos, la década de 1920. En el ritmo de un ciclo político específico (el gobierno de alianzas pluralistas lideradas por la clase media a través del Partido Radical), los Mensajes fueron una oportunidad coyuntural para reforzar el compromiso político con los aliados internacionales y también para fortalecer una agenda de identidad cultural e independencia económica.

En cuanto a la ola educativa nacionalista latinoamericana de la que formaron parte los Mensajes, la historiografía la ha iluminado con estudios tanto específicos como comparativos que prestan atención, entre otros factores, a los libros de texto y materiales escritos en las escuelas. Por ejemplo, Marta Nava ha analizado el nacionalismo educativo durante el régimen de Getulio Vargas en Brasil, haciendo hincapié en un ángulo que es notablemente significativo: la atención a las dimensiones emocionales de la vida escolar y el currículo se convirtió en un núcleo clave para el sistema educativo. Los estímulos sensoriales (mítines patrióticos; música; deportes) y el uso de material escrito con un atractivo emocional más explícito para los niños y niñas (no sin demostrar un lenguaje bastante sesgado en términos de roles de género) fueron instrumentos para este nuevo enfoque. Mediante la referencia a documentos oficiales de la Secretaria Brasileña de Educación, Nava ha demostrado cómo esta política exigía a los maestros que pusieran en marcha nuevas habilidades a medida que se les pedía dar a sus estudiantes "sugerencias emocionales, inspiradas en los sentimientos más altos del corazón humano [...] despertar el impulso heroico y el entusiasmo creativo en las almas de los jóvenes». ${ }^{11}$ Objetivos ideológicos a través de mensajes escritos y vínculos personales más estrechos entre profesores y estudiantes: una combinación que, moldeada por las circunstancias específicas nacionales, estuvo también presente en la educación chilena en el mismo período.

En una línea de análisis comparativo, Matthias Vom Hau ha explorado las correlaciones y diferencias entre los libros de texto oficiales que promovieron el nacionalismo patrocinado por el Estado en tres países latinoamericanos: México, Perú y Argentina. A pesar de que la investigación de Von Hau se trata de ciclos políticos nacionalistas en una escala cronológica más amplia que el caso chileno aquí presentado (que corresponde a un tramo marcado principalmente por la continuidad política y educacional bajo los gobiernos

\footnotetext{
${ }^{10}$ AL1N (Archivo del Liceo 1 de Niñas de Santiago). Crónica del Liceo. 1944, 1.

${ }^{11}$ Citado en Carmen Nava, "Lessons in Patriotism and Good Citizenship: National Identity and Public Schools during the Vargas Administration (1937-1945), Luso-Brazilian Review XXXV, 1 (1998): 44. (La traducción del fragmento es nuestra).
} 
encabezados por el partido radical), hay un par de cuestiones clave que son relevantes para entender nuestro análisis. La primera es una declaración teórica de Vom Hau que debe mantenerse a la vista, a pesar de las marcadas diferencias entre los libros de texto y el tipo de literatura educativa que podría coincidir con el formato de los Mensajes:

Los libros de texto no revelan los "hechos"; transmiten visiones particulares de la realidad social haciendo hincapié y restableciendo ciertos aspectos del mundo. Como artefactos culturales, los libros de texto son planeados, diseñados y distribuidos por actores con intereses reales. En particular, los estados son los actores clave en la conformación de los libros de texto. ${ }^{12}$

La consideración recién señalada es importante porque el espíritu de la época y las situaciones de coyuntura política se llevan a las escuelas con los Mensajes, en la medida que representan "intereses reales", pues constituyen una expresión más permanente de ellos a nivel institucional y /o de un individuo (en este caso, un factor en la propia agenda política personal de Velasco Claro).

Un segundo punto sugerente de la investigación de Vom Hau es que en los casos nacionales analizados el objetivo de fortalecer el carácter nacional estaba vinculado tanto a los objetivos económicos (desarrollo e independencia económica) como a los objetivos políticos (consenso social con un eje sobre la acción del Estado como conciliador). El proceso chileno compartió estas características, a pesar de que el régimen político estaba claramente menos comprometido con el liderazgo carismático. Debido a eso, alusiones personales a autoridades como el presidente Juan Antonio Ríos, del modo como fueron desplegadas en los Mensajes, podrían haber sido un ángulo polémico del discurso escrito de Claro Velasco. En su mensaje de diciembre de 1943 invocaba a los estudiantes chilenos de la siguiente forma:

\footnotetext{
elevad vuestros pensamientos a S.E., el presidente de la República, y agradecedle también a él lo mucho que hace por vosotros. Su acertada dirección de los negocios públicos y su preocupación constante por el bienestar de todos los ciudadanos, han sido determinantes del éxito que habéis logrado en este año. Juntad a su nombre el de su distinguida esposa, merced a cuyos esfuerzos tendrán este año, todos los niños, un regalo de Navidad. Que vuestra acción de gracias vaya a ellos con sincera devoción". ${ }^{13}$
}

Este tipo de apelaciones podría haber encajado adecuadamente en un régimen populista clásico con un culto a la personalidad como, por ejemplo, el que pocos años más tarde sucedería en Argentina con Juan Domingo Perón. No obstante, en el caso chileno parece haber tenido algún grado de resistencia de parte de algunos docentes, que criticaban la pertinencia de una excesiva personalización del mensaje del sistema educativo nacional a todas las escuelas en una sola voz (la de Claro Velasco), así como sus marcadas alusiones a la figura presidencial. Algo de ello puede notarse en el afán de un profesor, a fines

\footnotetext{
${ }_{12}$ Matthias Vom Hau, "Unpacking the school: textbooks, teachers and the construction of Nationhood in Mexico, Argentina and Peru", Latin American Research Review, 44, 3 (2009): 127-154. (La traducción del fragmento es nuestra).

${ }^{13}$ Claro Velasco, Mensajes a los niños de Chile, 82
} 
de 1943, de salir al paso frente algún grado de críticas y molestias que habían provocado los Mensajes:

algunas personas se han mostrado descontentas con la publicación de los Mensajes y estiman que el
dinero gastado en ellos sería más provechoso destinarlo a la compra de tiza u otro útil escolar, en vista
de la pobreza que aqueja en este sentido a las escuelas. Pero el dinero que demanda las publicaciones
es tan exiguo que con él no se subsanaría ninguna deficiencia que se pretenda remediar, y en cambio,
se privaría a los colegios de los valores espirituales que representan los Mensajes y al país de la
conciencia nacional y continental que se están fortaleciendo por medio de sus lecturas y comentarios. ${ }^{14}$

Las críticas a los Mensajes debían ser puestas en segundo plano frente a sus beneficios, de acuerdo con quienes, como el profesor recién citado, enfatizaban la necesidad de promover dicha "conciencia nacional y continental", tarea que tenía como antecedente cercano las iniciativas del denominado "Plan de Chilenidad", propiciado por el primer gobierno del Frente Popular, encabezado por Pedro Aguirre Cerda, a fines de $1941 .{ }^{15}$ El Plan sintonizaba, en algunos aspectos con lo que poco antes, en 1940, el Consejo Nacional de Educación en Argentina había establecido: el uso obligatorio de un folleto patriótico en todas las escuelas, mediante el que se buscaba establecer un refuerzo a los ideales nacionalistas y patrióticos, ensalzando medios afectivos para ello como los símbolos visuales y sonoros de la Patria. ${ }^{16}$

En continuidad con el espíritu recién señalado, tanto local como continental, el "Decreto sobre el Sentimiento Patrio" n-3791, promulgado en julio de 1941, profundizó en la idea de promoción afectiva del nacionalismo. En su quinto considerando, el texto legal sostenía "que no basta sentir el amor a la Patria, sino que es necesario exteriorizarlo, entre otras formas, en un alto respeto por las autoridades, las Instituciones y los Símbolos Nacionales". ${ }^{17}$ Resulta interesante la formulación de un propósito de regular, mediante su expresión material y visible, las disposiciones afectivas de las y los estudiantes. Y, por el contrario, el Decreto también estableció un conjunto de prohibiciones que también contribuían, en alguna medida, a establecer los límites estéticos de lo posible en tanto filiación patriótica y afectiva. Así, por ejemplo, no se podría exhibir en sitios públicos (incluyendo en éstos salas de clases, dormitorios, comedores, etc.) "símbolos extranjeros y retratos o efigies de gobernantes extranjeros". Se prohibía vincular la bandera nacional a otro tipo de símbolos y también el uso, por parte de profesores y estudiantes, "de insignias o distintivos que representen nacionalidades extranjeras o regímenes o ideologías políticas nacionales o extranjeras". Resulta interesante considerar que, aunque fuera por la vía de la omisión, el propósito de la política reflejado en el "Decreto sobre el Sentimiento Patrio" apelaba a aspectos sensoriales (en este caso, la vista), intentando asociar la imaginería "legítima" con aquella que diera cuenta de los valores patrios. No estaría lejana a la intención del le-

\footnotetext{
${ }^{14}$ Juan R. Díaz Roldán, "Comentarios a los Mensajes del Ministro de Educación", Boletín de Educación. Revista Oficial de Educación Primaria. Quinto Sector de Santiago, 3-4 (1943): 46.

${ }^{15}$ Sobre el Plan, consultar Barr-Melej, Reforming Chile, 205-210.

${ }^{16}$ Mariano Narodowski, y Laura Manolakis, "'Defending the 'Argentine Way of Life'. The State and School Textbooks in Argentina (1884-1984)", Paedagogica Historica 381 (2010): 309.

17 "Decreto sobre el sentimiento patrio", Revista de Educación Nacional XXVI 2 (1941): 11.
} 
gislador, probablemente, apartar del espacio escolar a la visualidad provenientes de otras fuentes: banderas, colores y signos de naciones en conflicto; de partidos políticos con apelación a la infancia y juventud; del imaginario de la penetrante cultura norteamericana, entre otros "enemigos" de una deseada identidad nacional en construcción.

La apelación a la vista para promover el nacionalismo educacional y para expandir una lectura a favor de los ideales democráticos y pacifistas se vio complementada, en esos años, por el intento de colonizar los afectos infantiles y juveniles a través del oído y en el hogar. Así, la autoridad educacional estableció, mediante el decreto n3489, la fundación de la Radio Escuela Experimental. El propósito de esta medida estatal era "implantar la radiodifusión educativa en Chile", para lo cual se contaría con el auxilio de siete emisoras a nivel nacional. ${ }^{18}$ Es interesante notar que parte importante de los contenidos que se presentaban en la programación (dirigida a estudiantes de primaria, profesores, a los hogares y al público en general) se vinculaba muy estrechamente a la promoción de los ya mentados ideales democráticos y latinoamericanistas. Del mismo modo, la Radio Escuela también llegó a ser una plataforma de difusión de los Mensajes a los Niños elaborados por el ministro Claro Velasco. Así, por ejemplo, en el horario programado para el domingo 4 de abril de 1943 se emitió una dramatización basada en "Maderos a la deriva", una de las cartas que la autoridad dirigió a las y los estudiantes chilenos. Otros temas en esta misma tónica serían emitidos en las semanas siguientes: "Homenaje al día de las Américas" (miércoles 14 de abril); "Chile, país democrático" (viernes 18 de junio); "La educación y la defensa de la democracia" (miércoles 30 de junio); "Sentido del Panamericanismo (14 de julio), etc.

El intento de promover un régimen emocional en torno a los valores nacionalistas, en la coyuntura de un ciclo histórico en el cual el nacionalismo era mirado tanto con esperanza como con fuerte crítica (dado que era identificado como una de las raíces de la conflagración mundial en curso), se apoyaba en la apelación a los sentidos, como se ha visto. Ella estaba orientada principalmente a afectar a las y los estudiantes. Sin embargo, también había en desarrollo una operación para galvanizar las convicciones nacionales, democráticas y civilistas de los profesores. En función de ello es que, en 1943, la Dirección General de Educación Primaria dio a luz la circular n49, mediante la cual se les pedía que tuvieran en cuenta algunos criterios fundamentales para interpretar correctamente las orientaciones nacionalistas empujadas por la autoridad ministerial. Es interesante notar la articulación del discurso nacionalista cívico en, a lo menos, dos de esos considerandos en que se solicitaba a cada docente:

$2^{\circ}$ que piense que ningún sistema educativo puede permanecer neutral frente a los planes sociales de una nación en marcha. Al contrario, dentro de una nación democrática, la educación debe decidirse con fe y valor por este sistema de convivencia, por sus ideales y convicciones, para luego difundirlos con espíritu racional e ilustrado en el seno del pueblo

${ }^{18}$ Ministerio de Educación Pública, Radio Escuela Experimental (Santiago: Imprenta Universitaria, 1943), 2. 
$3^{\circ}$ que reflexione en que, si la escuela no puede ser neutral en un sentido absoluto, tampoco puede estar al servicio de los grupos internos en conflicto que pretendan utilizarla para el fomento de sus particulares intereses. La escuela, como organismo de acción, es leal y está al servicio del plan de vida de la Nación, plan que supera todo tipo de fracciones o de grupos sociales, que define un programa fundamental de vida y que representa la voluntad democrática de todo un pueblo. ${ }^{19}$

En suma, podría ser sostenible la idea de que, en parte de la primera mitad de la década de 1940, las políticas educativas en Chile tuvieron como uno de sus propósitos configurar un régimen emocional, sustentado en la promoción de convicciones civilistas, patrióticas, latinoamericanistas, que se transmitieron tanto en registros explícitos (como, por ejemplo, las recién indicadas orientaciones para el profesorado primario) como mediante herramientas de apelación afectiva y sensorial (discursos leídos en cada escuela de Chile; una visualidad patriótica en las aulas promovida desde el Estado; una esfera auditiva de los valores propugnados por la autoridad mediante la radiofonía educativa). Ello impactó la vida escolar, sin duda. Ahora bien, la medida de dicho impacto suele ser más compleja de trazar debido al repertorio de fuentes disponibles y a la inefable distancia entre discursos y prácticas, entre propósitos formalizados en tinta y papel y experiencia efectivamente vivida. A continuación, con esas limitaciones en mente se bosqueja, de manera muy sucinta, algunos testimonios de cómo esas inducciones afectivas operaron en el espacio escolar.

\section{La guerra, los afectos y la escuela}

La apelación afectiva a lo patriótico en la educación chilena hunde sus raíces en episodios muy anteriores a la Segunda Guerra Mundial, sin duda. Es posible encontrar antecedentes en las celebraciones promovidas por las autoridades educacionales durante la Guerra del Pacífico (1879-1883), comprometidas con la formación de una imaginería patriótica militarista ${ }^{20}$. Desde entonces, los motivos nacionalistas se hicieron presentes de manera frecuente en las aulas. Mediante actos, desfiles estudiantiles, actividades cívicas y un amplio repertorio de acciones se promovió la adhesión a un nacionalismo que, a lo largo de la primera mitad del siglo XX, adquirió matices respecto a su contenido y sus inspiraciones. Desde una preocupación, al iniciar el siglo XX, que estaba centrada en lo que podría catalogarse como un "nacionalismo reactivo" frente a amenazas percibidas por los grupos oligárquicos a cargo del Estado (pavor frente a la desintegración social, por el influjo de las doctrinas anarquistas y el recrudecimiento del conflicto social; temor frente a la "decadencia de la raza", o sea, una preocupación con base higienista y resonancias darwinianas), hacia el período en estudio el nacionalismo había desarrollado un perfil menos militarista y políticamente más progresista. Tanto el énfasis en el discurso de solidaridad continental como los motivos pacifistas contrubuyeron a darle sustento a esta nueva

\footnotetext{
${ }^{19}$ Dirección General de Educación Primaria. Sección Pedagógica, Orientaciones socioeducativas para las Escuelas Primarias de Chile. Circular no49 (Santiago: Imprenta Quevedo, 1943), 9. Negrita en el original.

${ }^{20}$ Una buena caracterización de episodios de promoción del nacionalismo escolar en el libro de Jorge Rojas Flores, Historia de la infancia en el Chile Republicano. 1810-2010, Tomo I (1810-1950) (Santiago de Chile: Ediciones JUNJI, 2016), 175 y 253.
} 
versión, al interior de la que se inscribieron las manifestaciones que el régimen emocional perseguido por las autoridades tuvo en escuelas y liceos.

Como se ha señalado, la lectura de los Mensajes del ministro Claro Velasco formó parte de las inducciones afectivas al estudiantado. Apelando a la sensibilidad de niñas y niños, se les presentaba una lectura progresista, basada en la idea de una filiación común, respecto a lo que constituía la identidad americanista, marcando el contraste entre su homogeneidad y complementariedad política y cultural versus la división y la violencia imperantes en Europa. De tal modo, por ejemplo, lo debían entender las estudiantes del Liceo 1 de Niñas que, el viernes 14 de abril de 1944, asistieron en el patio de su establecimiento a una ceremonia literaria y artística americanista, que tuvo como punto central la lectura del mensaje "El continente de la hospitalidad". ${ }^{21}$

Una línea complementaria a las ceremonias públicas fue la promoción de la expresión de las y los estudiantes mediante creaciones literarias. En continuidad con un movimiento que venía desarrollándose en la educación chilena desde el último tercio del siglo XIX (con la formación de las primeras Academias Literarias en los liceos), hacia mediados de la década de 1940 existía un número interesante de periódicos y revistas escolares, presentes en distintas partes del país. Durante el período de la guerra, los temas relacionados con la paz, la democracia y la solidaridad aparecieron frecuentemente en sus páginas. La sensibilidad estudiantil frente al conflicto distante afloraba en composiciones literarias y cartas como, por ejemplo la que el niño Leandro Aliaga, de ocho a nueve años de edad, hacía llegar al periódico de su escuela. Residente en el puerto de Valparaíso, Leandro se manifestaba conmovido por la situación: "con mucha pena leo en los diarios las noticias de la guerra. Muchas hermosas ciudades han sido bombardeadas y antes tan bonitas, ahora no son más que escombros $(. . .)^{22}$. Más de dos mil kilómetros al sur, en la gélida, pequeña y aislada ciudad de Puerto Natales, Anselmo Godoy, un niño de edad semejante, expresaba más emotivamente sus sentimientos de solidaridad y dolor con los estudiantes de los países en guerra:

Estimados compañeros: les escribo estas cuantas líneas para expresarles lo que siento dentro de mi corazón de chileno. Como niño, cuando juego con mis compañeros, me acuerdo de ustedes que no pueden dar un paso que no encuentren con la muerte. No crean ustedes que nosotros somos enemigos de ustedes. Todo lo contrario. ¡Ojalá pudiéramos jugar, vivir juntos como hermanos! ${ }^{23}$

La inducción a que los niños y jóvenes tuvieran este tipo de ideaciones vicarias, en que compartían hipotéticos juegos con posible amigos lejanos y sufrientes y se ponían en el lugar de ellos (lo que, con el paso del tiempo, terminaría resumido en el término "empatía" erigido como guía deseable de las relaciones interpersonales) era un elemento necesario en la formulación de un régimen emocional. El estímulo y canalización de esas respuestas

\footnotetext{
${ }^{21}$ AL1N (Archivo del Liceo 1 de Niñas de Santiago). Crónica del Liceo. 1944,.2.

${ }^{22}$ Leandro Aliaga, "La Guerra", Antorcha. Órgano oficial de la Escuela Superior de Hombres, 1 (1944): 10.

${ }^{23}$ Anselmo Godoy, "Carta de un niño chileno a un niño europeo", El Amigo. Periódico infantil. Órgano de los alumnos de la Escuela Superior, nำ1 10 (1944): 7
} 
afectivas tuvo, pues, materialización en las performances ya comentadas (discursos, actos cívicos) y llegó a sobrevivir, gracias a la tinta y el papel, como palabra escrita, vestigio de afecto.

Finalmente, en la pequeña ciudad de Melipilla, emplazamiento articulador de un área eminentemente rural, Inés, alumna de cuarto año (presumiblemente, a sus nueve o diez años de edad) celebraba el fin de la guerra. En sus palabras de niña se hacía manifiesta su solidaridad y el dolor compartido con las víctimas del conflicto, así como su celebración de la llegada de la paz:

Paz, palabra sublime que llenas las almas de meditación y de grandezas (...) hemos elevado una plegaria al Dios Todopoderoso por los que tuvieron la triste suerte de morir lejos de su hogar, lejos de su Patria y que descansan su sueño eterno en territorio extraño, y por las madres que perdieron a sus hijos y por los hijos que no van a conocer a sus padres (... ${ }^{24}$

\section{Breves reflexiones finales}

El sábado 1 de julio de 1944, varias estudiantes de los cursos superiores del Liceo 1 de Niñas de Santiago concurrieron al cercano Teatro Real a escuchar las virtuosas interpretaciones del joven violinista polaco Henryk Szering (1918-1988) ${ }^{25}$. Habían sido invitadas por el propio músico durante la visita que él hizo al Liceo el miércoles anterior. Szering cumplía funciones de agente diplomático y cultural del gobierno polaco en el exilio desde 1939 (cuando conoció al general Wladyslaw Sikorski, que fungía como su primer ministro). La presencia de Szering en un establecimiento escolar en Chile, a miles de kilómetros de los frentes de guerra, era indicativa de la competencia que debían librar los bandos en pugna por atraer hacia sí las simpatías y afectos de países tan remotos: una escaramuza menor en una guerra diplomática que tuvo, en algún momento, involucrada a una comunidad escolar de niñas y adolescentes. La dimensión transnacional del conflicto se hacía evidente en una escala tan discreta como la de un recinto educacional a miles de kilómetros del frente de combate. La invitación de Szering a las colegialas era una manera de cumplir con su misión como enviado cultural pero también de agradecer la acogida brindada por el Liceo en su visita. Ese miércoles Cora Carreño, estudiante de VI año de Humanidades y presidenta de la Academia de Letras, había sido la vocera de la comunidad estudiantil y le había entregado, mediante la declamación de una poesía, un "mensaje amistoso a sus hermanitos polacos"26. Poesía, palabra, música fueron ingredientes de este involucramiento afectivo mediante el cual esas jóvenes estudiantes construyeron, aunque fuera solamente por un momento u obedeciera solamente a la exterioridad a la que obliga la tarea escolar y la hospitalidad, una filiación, un vínculo afectivo con esas niñas y niños lejanos y sufrientes. Hortensia, la niña de la "Oración a los Niños Polacos" y Cora, la joven

\footnotetext{
${ }^{24}$ Inés Román, "El triunfo de las democracias", Despertar. Periódico Escolar de la Escuela Superior, nำ11 16 (1945): 3.

${ }^{25}$ Una cronología de su vida, en la que se destaca su papel como agente cultural y diplomático del gobierno polaco en el exilio durante la Segunda Guerra Mundial y sus visitas a países de América Latina se encuentra disponible en Henryk Szering (1918-1988). http://www.henrykszeryng.net/chronology?lang=es.

${ }^{26}$ AL1N (Archivo del Liceo 1 de Niñas de Santiago). Crónica del Liceo, 1944, 12.
} 
declamando poesías a los "hermanitos polacos" fueron protagonistas de una inducción afectiva, de un deseado régimen emocional promovido por el Estado chileno mediante una plétora de medios destinados, en última instancia, a promover solidaridades vicarias frente a una guerra lejana pero, sobre todo, a solidificar lazos afectivos cotidianos con la comunidad imaginada en construcción.

Poniendo en perspectiva los hechos aquí narrados, tanto aquellos concernientes a la producción intencionada de un discurso patriótico, pacifista y civilista orientado a afectar a la infancia escolarizada (a través, por ejemplo, de los Mensajes) como también teniendo a la vista trazas de su impacto en las y los estudiantes mediante actos y textos literarios, resulta factible preguntarse por la impresión que tales eventos tuvieron al nivel de la experiencia de los sujetos. Es posible imaginar que las expectativas de una historiografía de la educación que intenta acercarse, en forma creciente, a la comprensión de las redes de intercambio de mensajes, símbolos, lenguajes y, en suma, afectos existentes en el hecho escolar puedan atesorar como un insumo útil una caracterización, anidada principalmente en lo textual y escrito, de un régimen emocional, como la que se ha buscado ofrecer acá. Sin embargo, cabe tener en cuenta que permanecen abiertas a exploración otras tantas dimensiones que constituyeron tales experiencias de afecto y de presencia vicaria de una infancia sufriente, invocada en las aulas escolares de un lejano país al sur del mundo. Así, desde las disciplinas que fijan su interés en las dimensiones afectivas de la realidad humana, se está generando una miríada de conceptualizaciones que, al ser reorientadas hacia el campo de estudio del pasado de la educación, pueden resultar muy sugerentes. Quede registrado, a título de mero ejemplo, cómo la idea de atmósfera podría orientar para aglutinar algunas de las referencias performativas que hemos traído a estas páginas. Al hacer alusión a las atmósferas, adoptamos provisoriamente una definición reciente, en el marco de los estudios sobre afectos, que la concibe como "modos en los que el mundo aparece o se fusiona en una situación indivisible e intensa o en el que un grupo de cuerpos llega a existir como un colectivo sentido. En este sentido, la atmósfera opera como un medio que hace aparecer lo que no puede deducirse de o reducirse a los cuerpos presentes en una situación"27. Un concepto como este abre ambiciosas avenidas y retos complejos a quien se interese por el campo de lo afectivo en el pasado educativo y surge como una ruta promisoria, cuyos pasos iniciales bien podrían ser aquellos a los que, para el tiempo y el espacio tratados, estas páginas han intentado contribuir.

\footnotetext{
${ }^{27}$ Friedlind Riedel, "Atmosphere", en Affective societies. Key concepts, ed. Jan Slavy y Christian von Scheve (Abingdon: Routledge, 2019), 85-95. La traducción de la frase es nuestra.

Partiendo de otros autores de referencia (como, por ejemplo, Jonathan Flatley), la historiadora Ana Abramowski ha sido pionera en la aplicación de este concepto para la historia de la educación argentina. Al respecto, por ejemplo, véase su artículo "La afectividad docente: narrativa sentimental, trabajo emocional y atmósferas afectivas en la labor de los maestros en Argentina (1920-1940)", Revista Brasileira de Historia da Educacão 18 (2018/2019), https://www.scielo.br/pdf/rbhe/v18/2238-0094-rbhe-18-e019.pdf. (Consultado em 27 de março de 2019)
} 


\section{Bibliografía}

\section{Fuentes primarias}

ALNSC (Archivo del Liceo de Hombres Neandro Schilling de San Fernando). Vr006 Crónica del Liceo de Hombres de San Fernando. 1931-1944.

AL1N (Archivo del Liceo 1 de Niñas de Santiago). Crónica del Liceo. 1944.

\section{Fuentes secundarias}

Abramowski, Ana Laura. "La afectividad docente: narrativa sentimental, trabajo emocional y atmósferas afectivas en la labor de los maestros en Argentina (1920-1940)". Revista Brasileira de Historia da Educacao 18 (2018/2019) https://www.scielo.br/ pdf/rbhe/v18/2238-0094-rbhe-18-e019.pdf. (Consultado em 27 de março de 2019)

Barr-Melej, Patrick. Reforming Chile: Nationalism, and the Rise of the Middle Class. Chapel Hill: University of North Carolina Press, 2001.

Claro Velasco, Benjamín. Mensajes a los niños de Chile, marzo de 1943-octubre de 1944. Santiago: Ediciones de la Universidad de Chile, 1945.

"Decreto sobre el sentimiento patrio". Revista de Educación Nacional XXVI 2 (1941): 11-12.

Dirección General de Educación Primaria. Sección Pedagógica. Orientaciones socioeducativas para las Escuelas Primarias de Chile. Circular n49. Santiago: Imprenta Quevedo, 1943.

Eustace, Nicole. "Emotions and political change". En Doing emotions history, editado por Susan Matt y Peter Stearns, 163-183. Urbana: University of Illinois Press, 2014.

Henryk Szering (1918-1988). http://www.henrykszeryng.net/chronology?lang=es (consultado en 11-04-2020).

Ministerio de Educación Pública. Radio Escuela Experimental. Santiago: Imprenta Universitaria, 1943.

Narodowski, Mariano and Laura Manolakis. "Defending the 'Argentine Way of Life'. The State and School Textbooks in Argentina (1884-1984)", Paedagogica Historica, 38 (1) (2002): 301-316.

Nava, Carmen. "Lessons in Patriotism and Good Citizenship: National Identity and Public Schools during the Vargas Administration (1937-1945). Luso-Brazilian Review, XXXV 1 (1998): 39-66.

Plamper, Jan. "Historia de las emociones: caminos y retos". Cuadernos de Historia Contemporánea 36 (2014): 17-29.

Reddy, William. The navigation of feeling. A framework for the history of emotions. Cambridge: Cambridge University Press, 2001. 
Riedel, Friedlind. "Atmosphere". En Affective societies. Key concepts, editado por Jan Slavy and Christian von Scheve, 85-95. Abingdon: Routledge, 2019.

Rinke, Stefan. Cultura de masas, reforma y nacionalismo en Chile 1910-1931. Santiago, DIBAM, 2002.

Rinke, Stefan, Encuentros con el Yanqui. Norteamericanización y cambio sociocultural en Chile (1898-1990). Santiago: DIBAM/LOM, 2014.

Rojas Flores, Jorge. Historia de la infancia en el Chile Republicano. 1810-2010. Tomo I (1810-1950). Santiago de Chile: Ediciones JUNJI, 2016.

Serrano, Sol, Macarena Ponce de León and Francisca Rengifo. Historia de la educación en Chile. 1810-2010. Tomo II: La educación nacional (1880-1930). Santiago de Chile: Taurus, 2013.

Toro-Blanco, Pablo. "Como se quiere a la madre o a la bandera: Notas sobre nacionalismo, ciudadanía y civilidad en la educación chilena (1910-1945)". En Nacionalismos e identidad nacional en Chile. Siglo XX. Volumen I, editado por Gabriel Cid and Alejandro San Francisco, 133-158. Santiago: Ediciones Bicentenario, 2010.

Vom Hau, Matthias. "Unpacking the school: textbooks, teachers and the construction of Nationhood in Mexico, Argentina and Peru". Latin American Research Review 44(3) (2009): 127-154. 